\title{
Perspective for Precision Medicine for Tuberculosis
}

\author{
Christoph Lange ${ }^{1,2,3,4,5 *}$, Rob Aarnoutse ${ }^{6}$, Dumitru Chesov ${ }^{1,2,3,7}$, Reinout van Crevel ${ }^{6}$, \\ Stephen H. Gillespie ${ }^{8}$, Hans-Peter Grobbel ${ }^{1,2,3}$, Barbara Kalsdorf ${ }^{1,2,3,4}$, \\ Irina Kontsevaya ${ }^{1,2,3}$, Arjan van Laarhoven ${ }^{6}$, Tomoki Nishiguchi ${ }^{9}$, Anna Mandalakas ${ }^{9}$, \\ Matthias Merker 2,4,10, Stefan Niemann 2,4,10, Niklas Köhler 1,2,3, Jan Heyckendorf 1,2,3, \\ Maja Reimann 1,2,3, Morten Ruhwald ${ }^{11}$, Patricia Sanchez-Carballo ${ }^{1,2,3}$, \\ Dominik Schwudke ${ }^{2,12,13}$, Franziska Waldow ${ }^{2,12}$ and Andrew R. DiNardo ${ }^{9}$
}

\section{OPEN ACCESS}

Edited by:

James Cheng-Chung Wei,

Chung Shan Medical University

Hospital, Taiwan

Reviewed by:

Daniel Scott-Algara,

Institut Pasteur, France Kuo-An Chu,

Kaohsiung Veterans General Hospital, Taiwan

*Correspondence: Christoph Lange clange@fz-borstel.de

Specialty section: This article was submitted to Inflammation,

a section of the journal

Frontiers in Immunology

Received: 28 May 2020 Accepted: 02 September 2020 Published: 08 October 2020

Citation:

Lange $C$, Aarnoutse $R$, Chesov D, van Crevel R, Gillespie SH, Grobbel H-P, Kalsdorf B, Kontsevaya I, van Laarhoven A, Nishiguchi T, Mandalakas A, Merker M, Niemann S, Köhler N, Heyckendorf J, Reimann M,

Ruhwald M, Sanchez-Carballo $P$,

Schwudke $D$, Waldow F and

DiNardo AR (2020) Perspective for Precision Medicine for Tuberculosis. Front. Immunol. 11:566608. doi: 10.3389/fimmu.2020.566608
${ }^{1}$ Division of Clinical Infectious Diseases, Research Center Borstel, Borstel, Germany, ${ }^{2}$ German Center for Infection Research (DZIF) Partner Site Borstel-Hamburg-Lübeck-Riems, Borstel, Germany, ${ }^{3}$ Respiratory Medicine and International Health, University of Lübeck, Lübeck, Germany, ${ }^{4}$ Cluster of Excellence Precision Medicine in Chronic Inflammation, Kiel, Germany, ${ }^{5}$ Department of Medicine, Karolinska Institute, Stockholm, Sweden, ${ }^{6}$ Department of Internal Medicine, Radboud Center of Infectious Diseases (RCl), Radboud University Medical Center, Nijmegen, Netherlands, ${ }^{7}$ Department of Pulmonology and Allergology, Nicolae Testemitanu University of Medicine and Pharmacy, Chisinau, Moldova, ${ }^{8}$ School of Medicine, University of St Andrews, St Andrews, United Kingdom, ${ }^{9}$ The Global Tuberculosis Program, Texas Children's Hospital, Immigrant and Global Health, Department of Pediatrics, Baylor College of Medicine, Houston, TX. United States, ${ }^{10}$ Molecular and Experimental Mycobacteriology, Research Center Borstel, Borstel, Germany, ${ }^{11}$ Foundation of Innovative New Diagnostics (FIND), Geneva, Switzerland, ${ }^{12}$ Bioanalytical Chemistry, Priority Area Infection, Research Center Borstel, Leibniz Lung Center, Borstel, Germany, ${ }^{13}$ Airway Research Center North, German Center for Lung Research (DZL), Borstel, Germany

Tuberculosis is a bacterial infectious disease that is mainly transmitted from human to human via infectious aerosols. Currently, tuberculosis is the leading cause of death by an infectious disease world-wide. In the past decade, the number of patients affected by tuberculosis has increased by $\sim 20$ percent and the emergence of drug-resistant strains of Mycobacterium tuberculosis challenges the goal of elimination of tuberculosis in the near future. For the last 50 years, management of patients with tuberculosis has followed a standardized management approach. This standardization neglects the variation in human susceptibility to infection, immune response, the pharmacokinetics of drugs, and the individual duration of treatment needed to achieve relapse-free cure. Here we propose a package of precision medicine-guided therapies that has the prospect to drive clinical management decisions, based on both host immunity and $M$. tuberculosis strains genetics. Recently, important scientific discoveries and technological advances have been achieved that provide a perspective for individualized rather than standardized management of patients with tuberculosis. For the individual selection of best medicines and host-directed therapies, personalized drug dosing, and treatment durations, physicians treating patients with tuberculosis will be able to rely on these advances in systems biology and to apply them at the bedside.

Keywords: precision medicine, tuberculosis, tailor-made regimen, mycobacterial genotypes, endotypes 


\section{INTRODUCTION}

Tuberculosis is the leading cause of death attributed to a single microbial pathogen world-wide (1). The World Health Organization (WHO) estimates, that in the year 2018 globally 10 million people newly developed tuberculosis and 1.5 million people died from this disease (1). Despite the enormous burden of tuberculosis on healthcare systems, especially in developing countries, research on new preventive and diagnostic methods and novel therapies against tuberculosis has gained new momentum only recently.

For the past five decades, patients with tuberculosis have received the same standard therapies without acknowledging differences in human immunity, pharmacokinetics or variations in the pathogenesis or of the causative microbe, Mycobacterium tuberculosis. Treatment was empiric or adopted to results of phenotypic drug-susceptibility testing that takes several weeks to months to become available. Patient-tailoring was limited to adjusting dosing to body weight, mostly in pediatric patients (2).
We have now entered an exciting era of medicine with major advances in the field of system biology and there is a realistic perspective that patients with tuberculosis will substantially benefit from these developments (3-5).

In the future, tuberculosis patient care may be individualized in at least 4 areas (Figure 1): (I) next generation sequencing of microbial $M$. tuberculosis DNA can predict drug susceptibility in the first week of diagnosis (6); (II) host immunity can be detrimentally suppressed and need augmenting or it can be detrimentally exuberant and need to be suppressed (79); or other forms of host genetic variability that may be specifically addressed by immune-based interventions (10), (III) individualized drug concentrations that can guide antimicrobial dosing (11), and (IV) biomarkers that predict relapse-free cure and can guide duration of required therapeutics (12) (Figure 1). Such stratified therapies are within reach and could soon become available for the clinical management of tuberculosis.

Precision Medicine refers to prevention and treatment strategies that take individual variability into account and predict,

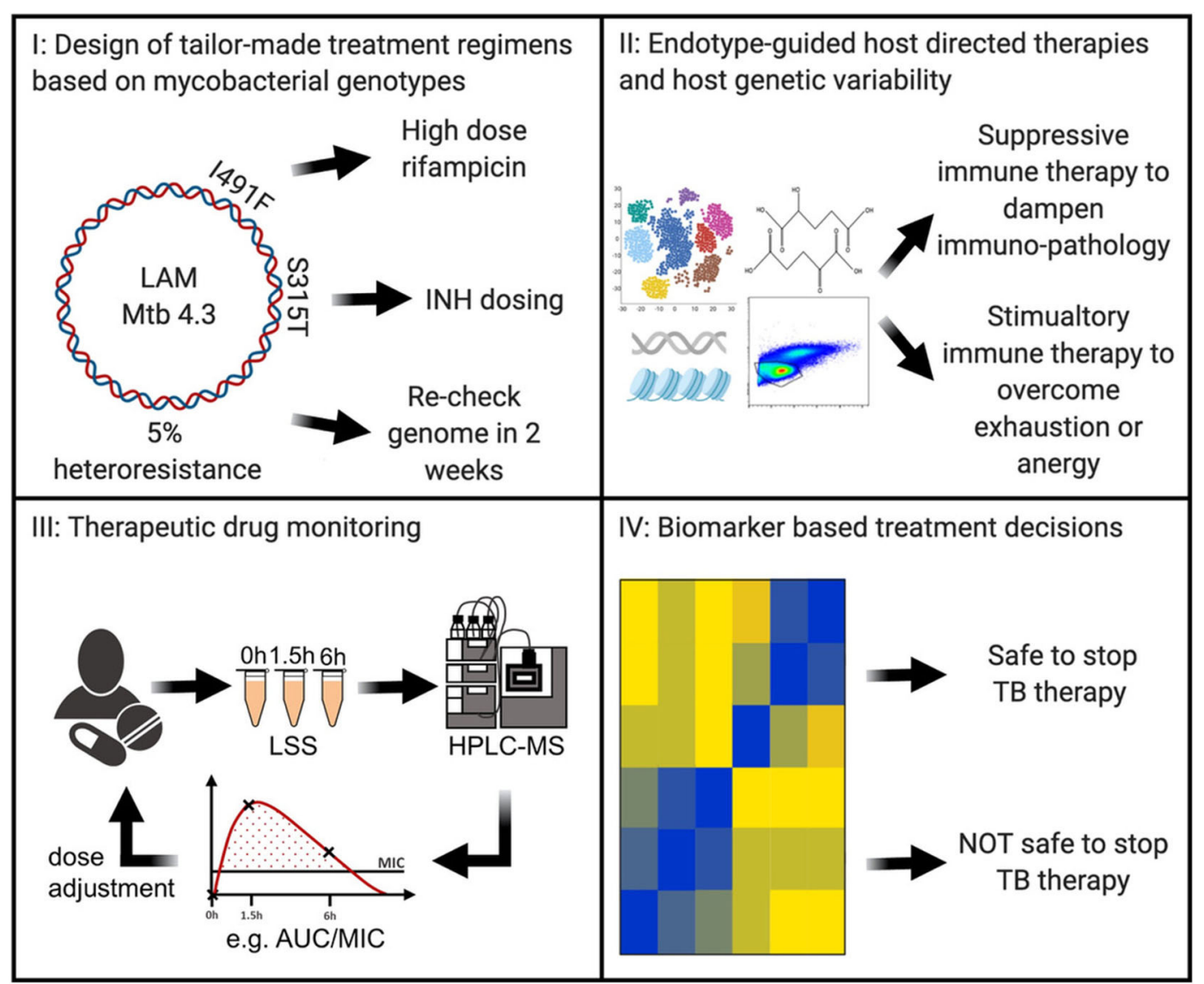

FIGURE 1 | In the near future, Precision Medicine for tuberculosis will likely include (I) antibiotic regimens based on next-generation sequencing of the Mycobacterium tuberculosis genome to guide tailor-made therapies; (II) evaluation of gene expression, genetic, epigenetic, metabolism, and/ or immune phenotyping to discern the host endotype with endotype-specific host directed therapies to shorten and improve clinical outcomes; (III) individualization of antibiotic dosing through therapeutic drug monitoring; (IV) in treatment biomarker levels to customize therapy duration. LAM, lipoarabinomannan; Mtb, Mycobacterium tuberculosis; INH, isoniazid; LSS, limited sampling strategy; HPLC-MS, high-performance liquid chromatography-mass spectrometry; AUC, area under the curve; MIC, minimal inhibitory concentration; TB, tuberculosis. 
who will benefit most from specific therapies and who will not. Taken together, Precision Medicine will improve patient outcome and reduce cost.

\section{SUBSECTIONS RELEVANT FOR THE SUBJECT}

\section{I: Design of Tailor-Made Treatment Regimens Based on Mycobacterial Genotypes}

Drug resistances in $M$. tuberculosis complex strains are exclusively mediated by genomic variants, mainly single nucleotide polymorphisms (SNPs) and small insertions/deletion (indels). Acquisition of resistance genes via plasmids or horizontal gene transfer does not occur (13). Accordingly, resistant phenotypes of $M$. tuberculosis complex strains mainly have a clear genetic correlate, which means SNPs can be used for resistance predictions with very high precision and are expected to replace phenotypic drug susceptibility testing (DST) in the future (13). The virtually complete interrogation of all resistance associated variants in genomes of clinical $M$. tuberculosis complex strains has become possible by advances of next generation sequencing (NGS) techniques. NGS allows for rapid sequencing of full genomes or targeted sequencing of resistance genes (amplicon sequencing) even directly from patient specimens, i.e., sputum (14-16). While genomic variant detection is of very high accuracy, genotypic drug susceptibility testing performance is strongly dependent on the underlying knowledge database (17). Although there is no standardized and globally adopted, "resistance mutation catalog" available yet, recent studies demonstrate that genotypic DST can predict resistance to the first-line drugs isoniazid, rifampicin, pyrazinamide with more than $90 \%$ sensitivity and more than $95 \%$ specificity, and thus would meet the WHO target product profile for molecular DST assays $(6,18)$. However, resistance prediction for some drugs, such as ethambutol and pyrazinamide is problematic due to breakpoint artifacts in phenotypic DSTs (19) or gaps in current knowledge databases, i.e., yet unknown resistance mutations.

There is emerging evidence that genotypic DST has a very good prediction for phenotypic drug susceptibility $(20,21)$ although for some drugs like PAS, D-cycloserine, thioamides, linezolid, meropenem-clavulanate, bedaquiline, clofazimine, and delamanid data are still limited. Programmes aiming to fill the knowledge gap in "geno-to-pheno" prediction such as CRyPTIC (www.crypticproject.org) and ReSeqTB (platform.reseqtb.org) are currently collecting genome sequencing data of global strain collection in combination with phenotypic DST data to further improve genotypic resistance predictions. Here, sequencing approaches represent an effective alternative to rapidly generate comprehensive resistance profiles of multidrug-resistant (MDR) strains allowing the design of a successful MDR-TB therapy for around $90 \%$ of the MDR-TB patients $(18,20)$.

Genotypic DST methods already provide accurate predictions for first-line anti-tuberculosis drugs and guide the design of MDR-TB therapies $(6,20)$. Sputum sequencing together with an improved interpretation catalog of drug resistance defining mutations will potentially allow genotypic DST to replace phenotypic DST for a large fraction of clinical $M$. tuberculosis complex strains.

\section{II: Endotype-Guided Host Directed Therapies and Host Genetic Variability}

Tuberculosis endotypes are the distinct molecular pathways through which an individual can progress to active tuberculosis. In a rough generalization, tuberculosis host immunity endotypes can be classified as immune deficient or as immune exuberant. The best described tuberculosis endotypes are deficiencies in interleukin (IL)-12, interferon (IFN)- $\gamma$ or tumor necrosis factor (TNF) pathways, which result in decreased intracellular killing of $M$. tuberculosis $(22,23)$. However, mouse and human studies also demonstrated that exuberant IFN- $\gamma$ or TNF is detrimental, resulting in pulmonary and macrophage necrosis and the escape of viable $M$. tuberculosis into extracellular space $(8,24-26)$. These studies demonstrate that a single immune correlate of protection is unlikely to be identified as the host immunity can not be either deficient or overly exuberant. Therefore, implementation of host-directed therapies (HDT) should preferably not be indiscriminate, but needs to be guided by the tuberculosis immune endotype. Preliminary work supports the identification of divergent host endotypes with contradictory metabolic, epigenetic, and immune gene expression endotypes (7), but these transcriptional studies lack corresponding functional studies.

In the pre-antibiotic era, treatment for tuberculosis was limited to host-directed therapy aiming at improving the nutritional and immune status of patients, e.g., with cod liver oil and sunlight (27), resulting in $\sim 20 \%$ survival rate for a period of at least 10 years (28). Harnessing and targeting host immunity, while minimizing immunopathology is the critical next phase in improving anti-tuberculosis therapy. Implementing endotype-specific host-directed therapy, first require proper characterization of the distinct tuberculosis endotypes in order to identify amendable targets. Tuberculosis dampens host immune responsiveness (29-33), and therefore transcriptomic and immune functional studies must be implemented both at baseline and upon antigenic stimulation. Since 1927, we have known that metabolism drives immunity (34) and modern studies are defining the metabolic-epigeneticimmune axis (35-39). Therefore, ideally, transcriptomic, metabolic, epigenetic and functional immune studies would be paired with robust clinical information that would allow for multi-modal data integration between molecular data and clinical outcomes. Finally, an immune deficient vs. immune exuberant model, while helpful, is overly simplistic as single cell studies have demonstrated deficiency in one arm of immunity, while exuberance in another. For example, tuberculosis induced hemophagocytic lymphohistiocytosis (HLH) is characterized by exuberant monocytes and deficient cytotoxic lymphocytes (40-43).

Endotype characterization studies likely will need to occur at disease diagnosis and again weeks into therapy. Tuberculosis is the archetypical chronic infection, hence host immunity after months of chronic antigenic stimulation is unlikely to 
resemble host immunity at the beginning of infection. Upon initial antigenic stimulation, modulated by inositol triphosphate receptors, there is an influx of calcium that helps stimulate glycolysis and activates nuclear factor of activated T-cells (NFAT) to translocate into the nucleus (44) as an example. When immune activation is chronic, NFAT switches from heterodimerizing with activator protein (AP)-1, to forming homodimers that drive anergy and thymocyte selection-associated high mobility group box protein TOX (TOX) and nuclear receptor 4A (NR4A) and epigenetic-mediated immune exhaustion (45-50). Therefore, drugs that modulate calcineurin-NFAT, such as cyclosporin A or tacrolimus, could detrimentally inhibit host immunity early in the disease process by blocking AP-1-NFAT heterodimers that drive beneficial immunity. In contrast, late in the disease process, these same drugs may be beneficial by blocking the detrimental NFAT homodimers that drive anergic and immune exhaustion responses. Evaluating endotypes could be operationalized by tests such as a mycobacterial growth inhibition assay, a test that has identified $\sim 50 \%$ of tuberculosis patients to have good mycobacterial killing capacity and $\sim 50 \%$ to have deficient killing capacity (51), and an ELISA based test, such as a modified version of the QuantiFERON-TB Gold in-tube assay or TSPOT.TB assay.

Host genetic studies have thus far largely focused on susceptibility to active tuberculosis $(52,53)$, to a lesser extent on susceptibility to infection (54) while the relationship between host genetic variability and treatment outcome is largely unexplored.

With regard to anti-tuberculous treatment, genetic studies have focused on drug exposure and toxicity ("pharmacogenetics"). The strongest association established is between $\mathrm{N}$-acetyltransferase (NAT)2-acetylator status and isoniazid drug concentrations, microbiological failure, relapse (55), and hepatotoxicity (56) and probably, genetic variation underlies rifampicin bioavailability and aminoglycosideinduced hearing loss (10). A next step would be "Mendelian randomization" studies: associating genetic loci predicting drug concentrations to treatment outcome (rather than toxicity). Then, pharmacogenetic trials could be initiated in which patients are randomized to standard treatment vs. genotype-based drug dosing.

In the most extreme disease phenotypes, targeted HDT may be most relevant. A Leukotriene A4 hydrolase (LTA4H) promotor genotype, important for the balance between proand anti-inflammatory eicosanoids (24), predicted cerebrospinal fluid leukocyte count. The hyper-inflammatory genotype was associated with improved survival in HIV-negative patients receiving corticosteroids $(57,58)$. In contrast, the same LTA4H genotype did not predict mortality in another cohort of patients (59), possibly because of higher disease severity, but the conflicting results could also be driven by genetic factors such as shorter regions of linkage disequilibrium or plasticity in the direction of the effect of the polymorphism (60). This shows that host genetic studies should be replicated in different settings. This can result in randomized controlled trials with stratification according to genotype, as is currently done in a study among patients with tuberculous meningitis, where only those with the hypo-inflammatory LTA4H genotype are randomized to receive corticosteroids or placebo (and all with a hyperinflammatory genotype receive corticosteroids) (61).

Genetic studies can be strengthened by an integrated or "cross-omics" approach. Among patients with tuberculous meningitis, using unbiased metabolomics, it was found that higher cerebrospinal fluid tryptophan, which can affect $M$. tuberculosis growth and central nervous system inflammation, was associated with higher mortality. Using a genome-wide association approach, so-called quantitative trait loci (QTLs) that associate with cerebrospinal fluid tryptophan levels were identified, and those same QTLs predicted survival in 285 other patients (62). The relevance of tryptophan metabolism, its genetic regulation, and the possible implications HDT are now being examined in more than 2,000 tuberculous meningitis patients (https://grantome.com/grant/NIH/R01-AI145781-01). Other "omics" data that could be used in such an integrated approach are transcriptional data or proteomics.

Future genetic studies will also benefit from precise patient characterization and combination with $M$. tuberculosis genotype (63), in a genome-to-genome approach (64). Also, replication studies in different settings, including relevant covariates, are needed and promising leads need to be trailed in studies focusing on outcome to identify genetic variants important in treatment decisions.

\section{III: Therapeutic Drug Monitoring}

Therapeutic drug monitoring (TDM) is the concept of individualizing drug dosing by measuring the drug concentration in a patient's serum/plasma and adjusting the dose accordingly.

Consequently, TDM is indicated in settings with a risk of low or high tuberculosis drug exposures: presence of altered drug absorption, distribution, metabolism, or excretion (e.g., renal insufficiency), comorbidities that may affect exposure to antituberculosis drugs [HIV infection, diabetes mellitus (65)], drugdrug interactions, and in patients who are slow to respond or with relapsed tuberculosis (66).

Low anti-tuberculosis drug concentrations can lead to inefficient mycobacterial killing, treatment failure, relapse and selection of drug resistance (67), whereas high concentrations may increase the risk of adverse effects (68).

The TDM process comprises (1) obtaining blood samples, (2) measuring drug concentrations, and (3) interpreting the results.

1. The optimal sampling time points and the number of samples depend on the assessed drug. Limited sampling strategies (LSS) predict the most informative sampling time points based on population pharmacokinetic data, i.e., "average" exposures from tuberculosis patients. With the help of LSS, sampling can often be reduced to three or less time points $(69,70)$.

2. Analysis of the serum/plasma samples is ideally performed with high performance liquid chromatography mass spectrometry (HPLC-MS). HPLC-MS is highly sensitive and specific and allows simultaneous analysis of several tuberculosis drugs in one run of the assay (71).

3. The degree of exposure that is effective depends on the susceptibility of the patient's $M$. tuberculosis strain, as 
TABLE 1 | Current standards and future perspectives for Precision Medicine for tuberculosis.

\begin{tabular}{ll}
\hline Measure & Current standard \\
\hline Rapid selection of effective & Rapid molecular Rifampicin-resistance \\
anti-tuberculosis drugs to form a & testing followed by phenotypic drug \\
treatment regimen. & $\begin{array}{l}\text { susceptibility testing in liquid and/or solid } \\
\text { media cultures. }\end{array}$
\end{tabular}

Supporting the host immunity by endotype-guided decisions for host-directed therapies.
Endotypes of tuberculosis are still not well defined and identification of endotypes to guide host directed therapies is not performed at present.
Analysis of host genetic variability to predict adverse events and to provide precise therapeutically interventions.

Therapeutic drug monitoring.

Individualizing the duration of anti-tuberculosis therapy.
Host genetic markers are currently not identified in clinical practice. At specialized centers and on special request genetic markers such as mutations associated with specific immune deficiencies are evaluated.

Only very few centers world-wide perform measurement of drug levels and PK/PD profiles of anti-tuberculosis drugs in routine clinical practice. Even at these centers there are no analytic capacities to monitor several of the 2nd-line anti-tuberculosis drugs.

There are no biomarkers available for routine clinical practice to guide clinicians in the decision of the duration of anti-tuberculosis therapy.
Future perspective for precision medicine

Rapid, sputum-based automated sequencing of the entire genome of $M$. tuberculosis or of genetic regions (amplicons) of the genome of $M$. tuberculosis where mutations do predict drug resistance. Algorithm-based treatment decisions based on molecular prediction of drug resistance.

Optimal testing needs to be discerned, but likely will include a mixture of metabolism, genetic, epigenetic and/or immune functional studies to identify the host endotype. For example, if host immunity was found to be exuberant, then an endotype-specific therapy might consist of a glucocorticoid, NSAID, calcineurin inhibitor (cyclosporin or tacrolimus) or mTOR inhibitor (rapamycin). In contrast, if evaluations identified anergic or exhausted immunity, than immune boosting regimens may be chosen.

Genetic testing before the start of treatment to (1) define dosing of anti-tuberculous treatment and to (2) identify patients susceptible to adverse drug events and (3) to tailor host-directed therapy to the individual patient.

Regular therapeutic drug monitoring with same-day-results for all anti-tuberculosis drugs for individual dosage adjustments.

Defining the duration of therapy to achieve relapse-free cure based on the measurement of a robust validated biomarker that also identifies patients having the risk for experiencing recurrent disease at early time points during therapy. Ideally, this biomarker should be measurable in a point-of-care test system.
When to apply

At the time of diagnosis.

Within the first week: of the diagnosis. Should be repeated $4-8$ weeks to evaluate dynamic transitions.

At the time of diagnosis.

For the first month once a week, once a month thereafter throughout the course of treatment.

Once a month throughout the course of treatment starting at month 4. reflected in the minimal concentration that inhibits growth of $M$. tuberculosis (minimal inhibitory concentration-MIC). Dependent on the drug's mode of action, targets are defined as area under the curve (AUC)/MIC, maximal concentration (Cmax)/MIC, or time above MIC (T>MIC). Unfortunately, specific targets are not yet available for anti-tuberculosis drugs and MIC is seldomly determined. Alternatively, drug concentrations are compared to population pharmacokinetic data (66).

Linking NGS data for prediction of minimal inhibitory concentrations (MIC) with TDM data is a very promising concept to provide tailored high-dosage therapies in cases of low level bacillary drug resistance $(21,72)$. More clinical information will be needed to proof the plausible assumption that mutations in the genome of $M$. tuberculosis corresponding with a mildly elevated MICs to specific medicines can be overcome by a higherdose administered of these drugs.

There is a disparity between tuberculosis prevalence and available resources for its treatment. TDM is highly resourceintensive with limited reimbursement available to offset cost. As health care providers avoid the costs of purchase and maintenance of equipment without reimbursement, very few centers have implemented TDM in their routine clinical practice. Ideally, results should be available and interpreted within days in order to effectively adjust therapies. New sampling techniques $(73,74)$, development of automated analytical techniques (immuno-assays) and in-vitro models that help to substantiate target values (75) will facilitate its roll-out. TDM integrates information on drug pharmacokinetics and mycobacterial susceptibility to ensure efficacy and prevent toxicity. It could improve the use of currently available drug therapy and individualized high-dose treatments may even overcome some forms of resistance.

\section{IV: Biomarker Based Treatment Decisions}

An ideal treatment monitoring test would have a 1-2 day turnaround, be available and implementable in resource constrained settings and could accurately identify when tuberculosis therapy can be terminated to minimize excess treatment. Molecular tests such as the GeneXpert (Cepheid, USA) or the line-probe assays (Hain Life Sciences, Nehren, Germany) are commercially available as rapid diagnostic methods that permit drug-resistance prediction for important first- and second-line drugs $(76,77)$. As an alternative, transrenal DNA, and lipoarabinomannan 
(LAM) detection in urine have been described to diagnose active tuberculosis in people living with HIV (78-80). Screening for tuberculosis with a LAM urine assay in African people living with HIV and low CD4 count lead to a significant decrease in mortality (81). A novel assay with increased sensitivity may even have a larger impact for the management of HIV-associated tuberculosis (82). As an alternative, the detection of mycobacterial DNA from stool samples of patients with tuberculosis highly correlated with sputum-based diagnostic results and were also able to identify patients at risk for experiencing therapy failure (83).

Immunological assays could improve outcomes in populations in whom diagnosis is very difficult, such as children in whom reports of the T-cell activation marker (TAM-TB) test suggest a sensitivity and specificity of $\sim 83$ and $97 \%$, respectively (84). Complex analysis of transcriptomic studies from whole blood have indicated RNA signatures to be associated with future active tuberculosis although the applicability of such tools in a low or middle income country context is uncertain (85-87). However, a recent systematic review and patient-level pooled meta-analysis concluded that blood transcriptional biomarkers reflect only short-term risk of active tuberculosis and surpass WHO benchmarks only if applied to 3-6-month intervals (88).

In addition, certain computer-aided diagnostic (CAD) tools may be able to identify tuberculosis patients with high accuracy (specificity of $98 \%$ and of sensitivity $90 \%$ ) from digital chest-Xray images (89).

Mycobacterial culture is the most relevant measure of treatment response, but mycobacterial growth is slow and, as treatment progresses, the time to a positive result increases (90). Here, rapid molecular tests detecting only viable bacteria such as the molecular bacterial load assay (MBLA) may be promising for the future treatment monitoring of tuberculosis patients (91). The MBLA correlates with the time to liquid culture positivity. The advantage is that it is rapid and not compromised by contamination of culture. MBLA test results correlates with disease severity, and provide information on the bactericidal effect of different drugs and drug regimens (91-93). As a rapid test measuring the number of viable organisms in a few hours it has potential to identify failing patients. This could suggest infection with a resistant organism or non-adherence and enable additional investigations or alternatively provide reassurance that the patient is responding appropriately. Operational trials to explore this are now underway.

Phenotypic changes on M. tuberculosis-specific blood T cells may be able to inform about treatment efficacy as shown in adults and in children $(94,95)$. Modern imaging techniques such as PET-CT scans may correlate with treatment responses, but

\section{REFERENCES}

1. World Health Organization. Global Tuberculosis Report 2019 Geneva. (2019).

2. Horsburgh CR Jr, Barry CE, 3rd, Lange C. Treatment of tuberculosis. $N$ Engl J Med. (2015) 373:2149-60. doi: 10.1056/NEJMra14 13919 alone were not accurate enough to precisely identify patients with recurrent disease in South Africa (96). Interestingly, certain RNA signatures could predict recurrent disease in tuberculosis patients $(97,98)$. However, these biomarkers have not been prospectively evaluated and markers that could individualize the duration of therapy are missing so far.

\section{DISCUSSION}

With technological advances in the field of diagnostics, analytics, and integration of comprehensive data-sets, tailor-made Precision Medicine for patients with tuberculosis is within reach at centers that operate on the frontier of translational research (Table 1). As independent measures, genotypic prediction of phenotypic $M$. tuberculosis drug-resistance based on information of entire bacterial genomes, genotypic and phenotypic identification of immune endotypes and human susceptibility to tuberculosis to individualize HDT, and novel biomarkers guiding physicians for individual treatment decisions are already in place at highly specialized centers and usually under research conditions. The clinical application of some of these innovations needs to become the medical standard. However, as a poverty-related disease, the majority of patients affected by tuberculosis live in resource limited settings. Finding funding and performing operational research on the implementation of precision medicine for tuberculosis in these settings will be one of the great challenges for the future.

\section{AUTHOR CONTRIBUTIONS}

All authors made a contribution to the acquisition of the information for the work, critically revised the manuscript for important intellectual content, and gave final approval of the current version to be published. All authors agree to be accountable for all aspects of the work in ensuring that questions related to the accuracy or integrity of any part of the work are appropriately investigated and resolved.

\section{FUNDING}

German Center for Infection Research (DZIF) Clinical TB TTUTB 02.704.

\section{ACKNOWLEDGMENTS}

The publication of this article was supported by the Open Access Publication Fund of the Leibniz Association.

3. Lange C, Alghamdi WA, Al-Shaer MH, Brighenti S, Diacon AH, DiNardo AR, et al. Perspectives for personalized therapy for patients with multidrug-resistant tuberculosis. J Intern Med. (2018) 284:16388. doi: $10.1111 /$ joim. 12780

4. Salzer HJ, Wassilew N, Kohler N, Olaru ID, Gunther G, Herzmann $\mathrm{C}$, et al. Personalized medicine for chronic respiratory infectious diseases: tuberculosis, nontuberculous mycobacterial pulmonary 
diseases, and chronic pulmonary aspergillosis. Respiration. 92:199-214. doi: 10.1159/000449037

5. Olaru ID, Lange C, Heyckendorf J. Personalized medicine for patients with MDR-TB. J Antimicrob Chemother. (2016) 71:852-5. doi: 10.1093/jac/ dkv354

6. Consortium CR, the GP, Allix-Beguec C, Arandjelovic I, Bi L, Beckert $\mathrm{P}$, et al. Prediction of susceptibility to first-Line tuberculosis drugs by DNA sequencing. N Engl J Med. (2018) 379:1403-15. doi: 10.1056/NEJMoa 1800474

7. DiNardo AR, Rajapakshe K, Gandhi T, Grimm S, Nishiguchi T, Heyckendorf J, et al. Discerning divergent tuberculosis endotypes: a meta-analysis and systematic review of individual patient data. medRxiv [priprint]. (2020). doi: 10.1101/2020.05.13.20100776

8. Barber DL, Mayer-Barber KD, Feng CG, Sharpe AH, Sher A. CD4t cells promote rather than control tuberculosis in the absence of $\mathrm{PD}$-1-mediated inhibition. J Immunol. (2011) 186:1598-607. doi: 10.4049/jimmunol.1003304

9. Roca FJ, Ramakrishnan L. TNF dually mediates resistance and susceptibility to mycobacteria via mitochondrial reactive oxygen species. Cell. (2013) 153:52134. doi: 10.1016/j.cell.2013.03.022

10. Abel L, Fellay J, Haas DW, Schurr E, Srikrishna G, Urbanowski M, et al. Genetics of human susceptibility to active and latent tuberculosis: present knowledge and future perspectives. Lancet Infect Dis. (2018) 18:e64e75. doi: 10.1016/S1473-3099(17)30623-0

11. Magis-Escurra C, van den Boogaard J, Ijdema D, Boeree M, Aarnoutse R. Therapeutic drug monitoring in the treatment of tuberculosis patients. Pulm Pharmacol Ther. (2012) 25:83-6. doi: 10.1016/j.pupt.2011.12.001

12. Heyckendorf J, Olaru ID, Ruhwald M, Lange C. Getting personal perspectives on individualized treatment duration in multidrug-resistant and extensively drug-resistant tuberculosis. Am J Respir Crit Care Med. (2014) 190:37483. doi: $10.1164 / \mathrm{rccm} .201402-0363 \mathrm{PP}$

13. Meehan CJ, Goig GA, Kohl TA, Verboven L, Dippenaar A, Ezewudo $\mathrm{M}$, et al. Whole genome sequencing of Mycobacterium tuberculosis: current standards and open issues. Nat Rev Microbiol. (2019) 17:53345. doi: 10.1038/s41579-019-0214-5

14. Ng KCS, Supply P, Cobelens FGJ, Gaudin C, Gonzalez-Martin J, de Jong $\mathrm{BC}$, et al. How well do routine molecular diagnostics detect rifampin heteroresistance in Mycobacterium tuberculosis? J Clin Microbiol. (2019) 57:11. doi: 10.1128/JCM.00717-19

15. Doyle RM, Burgess C, Williams R, Gorton R, Booth H, Brown J, et al. Direct whole-Genome sequencing of sputum accurately identifies drug-Resistant Mycobacterium tuberculosis faster than MGIT culture sequencing. J Clin Microbiol. (2018) 56:18. doi: 10.1128/JCM.00666-18

16. Feuerriegel S, Kohl TA, Utpatel C, Andres S, Maurer FP, Heyckendorf J, et al. Rapid genomic first- and second-line drug resistance prediction from clinical Mycobacterium tuberculosis specimens using deeplex(R)-MycTB. Eur Respir J. (2020) doi: 10.1183/13993003.01796-2020. [Epub ahead of print].

17. Schleusener V, Koser CU, Beckert P, Niemann S, Feuerriegel S. Mycobacterium tuberculosis resistance prediction and lineage classification from genome sequencing: comparison of automated analysis tools. Sci Rep. (2017) 7:46327. doi: 10.1038/srep46327

18. Hunt M, Bradley P, Lapierre SG, Heys S, Thomsit M, Hall MB, et al. Antibiotic resistance prediction for Mycobacterium tuberculosis from genome sequence data with mykrobe. Wellcome Open Res. (2019) 4:191. doi: 10.12688/wellcomeopenres.15603.1

19. Angeby K, Jureen P, Kahlmeter G, Hoffner SE, Schon T. Challenging a dogma: antimicrobial susceptibility testing breakpoints for Mycobacterium tuberculosis. Bull World Health Organ. (2012) 90:693-8. doi: 10.2471/BLT.11.096644

20. Heyckendorf J, Andres S, Koser CU, Olaru ID, Schon T, Sturegard E, et al. What is resistance? Impact of phenotypic versus molecular drug resistance testing on therapy for multi- and extensively drug-resistant tuberculosis. Antimicrob Agents Chemother. (2018) 62:2. doi: 10.1128/AAC.01550-17

21. Gygli SM, Keller PM, Ballif M, Blochliger N, Homke R, Reinhard M, et al. Whole-Genome sequencing for drug resistance profile prediction in Mycobacterium tuberculosis. Antimicrob Agents Chemother. (2019) 63:18. doi: 10.1128/AAC.02175-18

22. Bustamante J, Boisson-Dupuis S, Abel L, Casanova JL. Mendelian susceptibility to mycobacterial disease: genetic, immunological, and clinical features of inborn errors of IFN-gamma immunity. Semin Immunol. (2014) 26:454-70. doi: 10.1016/j.smim.2014.09.008

23. Ehlers $\mathrm{S}$. Role of tumour necrosis factor (TNF) in host defence against tuberculosis: implications for immunotherapies targeting TNF. Ann Rheum Dis. (2003) 62(Suppl. 2):37-42. doi: 10.1136/ard.62.suppl_2.ii37

24. Tobin DM, Vary JC, Jr., Ray JP, Walsh GS, Dunstan SJ, et al. The lta4h locus modulates susceptibility to mycobacterial infection in zebrafish and humans. Cell. (2010) 140:717-30. doi: 10.1016/j.cell.2010.02.013

25. Tobin DM, Roca FJ, Oh SF, McFarland R, Vickery TW, Ray JP, et al. Host genotype-specific therapies can optimize the inflammatory response to mycobacterial infections. Cell. (2012) 148:434-46. doi: 10.1016/j.cell.2011.12.023

26. Sakai S, Kauffman KD, Sallin MA, Sharpe AH, Young HA, Ganusov $\mathrm{VV}$, et al. CD4t Cell-Derived IFN-gamma plays a minimal role in control of pulmonary Mycobacterium tuberculosis infection and must be actively repressed by PD-1 to prevent lethal disease. PLoS Pathog. (2016) 12:e1005667. doi: 10.1371/journal.ppat.1005667

27. Brighenti S, Bergman P, Martineau AR. Vitamin $d$ and tuberculosis: where next? J Intern Med. (2018) 284:145-62. doi: 10.1111/joim.12777

28. Tattersall WH. The survival of sputum-positive consumptives. A study of 1,192 cases in a county borough between 1914 and 1940. Tubercle. (1947) 28:109-14.

29. Furcolow ML, Emge ME, Bunnell IL. Depression of tuberculin and histoplasmin sensitivity associated with critical illness. Public Health Rep. (1948) 63:1290-8. doi: 10.2307/4586715

30. Michael L, Furcolow BH, Nelson WE, Palmer CE. Quantitative studies of the tuberculin reaction: i. titration of tuberculin sensitivity and its relation to tuberculous infection. Public Health Rep. (1941) 56:1082100. doi: $10.2307 / 4583745$

31. DiNardo A, Rajapakshe K, Nishiguchi T, Mtetwa G, Grimm SL, Dlamini Q, et al. DNA hyper-methylation during tuberculosis dampens host immune responsiveness. J Clin Invest. (2020) 130:3113-123. doi: 10.1172/JCI134622

32. Sahiratmadja E, Alisjahbana B, de Boer T, Adnan I, Maya A, Danusantoso $\mathrm{H}$, et al. Dynamic changes in pro- and anti-inflammatory cytokine profiles and gamma interferon receptor signaling integrity correlate with tuberculosis disease activity and response to curative treatment. Infect Immun. (2007) 75:820-9. doi: 10.1128/IAI.00602-06

33. Singh A, Mohan A, Dey AB, Mitra DK. Inhibiting the programmed death 1 pathway rescues Mycobacterium tuberculosis -specific interferon gammaproducing $t$ cells from apoptosis in patients with pulmonary tuberculosis. $J$ Infect Dis. (2013) 208:603-15. doi: 10.1093/infdis/jit206

34. Warburg O, Wind F, Negelein E. The metabolism of tumors in the body. J Gen Physiol. (1927) 8:519-30. doi: 10.1085/jgp.8.6.519

35. Cheng SC, Quintin J, Cramer RA, Shepardson KM, Saeed S, Kumar V, et al. mTOR- and HIF-1alpha-mediated aerobic glycolysis as metabolic basis for trained immunity. Science. (2014) 345:1250684. doi: 10.1126/science.12 50684

36. Palsson-McDermott EM, Curtis AM, Goel G, Lauterbach MAR, Sheedy FJ, Gleeson LE, et al. Pyruvate kinase $\mathrm{m} 2$ regulates hif-1alpha activity and IL-1beta induction and is a critical determinant of the warburg effect in LPS-Activated macrophages. Cell Metab. (2015) 21:347. doi: 10.1016/j.cmet.2015.01.017

37. Mills EL, Kelly B, Logan A, Costa ASH, Varma M, Bryant CE, et al. Succinate dehydrogenase supports metabolic repurposing of mitochondria to drive inflammatory macrophages. Cell. (2016) 167:457-70 e13. doi: 10.1016/j.cell.2016.08.064

38. Netea MG, Joosten LA, Latz E, Mills KH, Natoli G, Stunnenberg HG, et al. Trained immunity: a program of innate immune memory in health and disease. Science. (2016) 352:aaf1098. doi: 10.1126/science.aaf1098

39. Arts RJW, Carvalho A, La Rocca C, Palma C, Rodrigues F, Silvestre R, et al. Immunometabolic pathways in BCG-Induced trained immunity. Cell Rep. (2016) 17:2562-71. doi: 10.1016/j.celrep.2016.11.011

40. Padhi S, Ravichandran K, Sahoo J, Varghese RG, Basheer A. Hemophagocytic lymphohistiocytosis: an unusual complication in disseminated Mycobacterium tuberculosis. Lung India. (2015) 32:593-601. doi: 10.4103/0970-2113.168100

41. Prada-Medina CA, Fukutani KF, Pavan Kumar N, Gil-Santana L, Babu $\mathrm{S}$, Lichtenstein F, et al. Systems immunology of diabetes-Tuberculosis 
comorbidity reveals signatures of disease complications. Sci Rep. (2017) 7:1999. doi: 10.1038/s41598-017-01767-4

42. Lachmandas E, Thiem K, van den Heuvel C, Hijmans A, de Galan BE, Tack CJ, et al. Patients with type 1 diabetes mellitus have impaired IL-1beta production in response to Mycobacterium tuberculosis. Eur J Clin Microbiol Infect Dis. (2018) 37:371-80. doi: 10.1007/s10096-017-3145-y

43. Ronacher K, van Crevel R, Critchley JA, Bremer AA, Schlesinger LS, Kapur $A$, et al. Defining a research agenda to address the converging epidemics of tuberculosis and diabetes: part 2: underlying biologic mechanisms. Chest. (2017) 152:174-80. doi: 10.1016/j.chest.2017.02.032

44. Trebak M, Kinet JP. Calcium signalling in t cells. Nat Rev Immunol. (2019) 19:154-69. doi: 10.1038/s41577-018-0110-7

45. Valdor R, Macian F. Induction and stability of the anergic phenotype in t cells. Semin Immunol. (2013) 25:313-20. doi: 10.1016/j.smim.2013.10.010

46. Lynn RC, Weber EW, Sotillo E, Gennert D, Xu P, Good Z, et al. c-Jun overexpression in CAR t cells induces exhaustion resistance. Nature. (2019) 576:293-300. doi: 10.1038/s41586-019-1805-Z

47. Yao C, Sun HW, Lacey NE, Ji Y, Moseman EA, Shih HY, et al. Single-cell RNAseq reveals TOX as a key regulator of $\mathrm{CD} 8(+) \mathrm{t}$ cell persistence in chronic infection. Nat Immunol. (2019) 20:890-901. doi: 10.1038/s41590-019-0403-4

48. Seo H, Chen J, Gonzalez-Avalos E, Samaniego-Castruita D, Das A, Wang YH, et al. TOX and TOX2 transcription factors cooperate with NR4A transcription factors to impose CD8(+) t cell exhaustion. Proc Natl Acad Sci USA. (2019) 116:12410-5. doi: 10.1073/pnas.1905675116

49. Khan O, Giles JR, McDonald S, Manne S, Ngiow SF, Patel KP, et al. TOX transcriptionally and epigenetically programs CD8(+) t cell exhaustion. Nature. (2019) 571:211-8. doi: 10.1038/s41586-019-1325-x

50. Alfei F, Kanev K, Hofmann M, Wu M, Ghoneim HE, Roelli P, et al. TOX reinforces the phenotype and longevity of exhausted t cells in chronic viral infection. Nature. (2019) 571:265-9. doi: 10.1038/s41586-019-1326-9

51. Joosten SA, van Meijgaarden KE, Arend SM, Prins C, Oftung F, Korsvold GE, et al. Mycobacterial growth inhibition is associated with trained innate immunity. J Clin Invest. (2018) 128:1837-51. doi: 10.1172/JCI97508

52. Thye T, Vannberg FO, Wong SH, Owusu-Dabo E, Osei I, Gyapong J, et al. Genome-wide association analyses identifies a susceptibility locus for tuberculosis on chromosome 18q11.2. Nat Genet. (2010) 42:73941. doi: 10.1038/ng1011-1040a

53. Thye T, Owusu-Dabo E, Vannberg FO, van Crevel R, Curtis J, Sahiratmadja $\mathrm{E}$, et al. Common variants at $11 \mathrm{p} 13$ are associated with susceptibility to tuberculosis. Nat Genet. (2012) 44:257-9. doi: 10.1038/ng.1080

54. Schurr E. The contribution of host genetics to tuberculosis pathogenesis. Kekkaku. (2011) 86:17-28.

55. Pasipanodya JG, Srivastava S, Gumbo T. Meta-analysis of clinical studies supports the pharmacokinetic variability hypothesis for acquired drug resistance and failure of antituberculosis therapy. Clin Infect Dis. (2012) 55:169-77. doi: 10.1093/cid/cis353

56. Cai Y, Yi J, Zhou C, Shen X. Pharmacogenetic study of drugmetabolising enzyme polymorphisms on the risk of anti-tuberculosis drug-induced liver injury: a meta-analysis. PLoS ONE. (2012) 7:e47769. doi: 10.1371/journal.pone.0047769

57. Tobin DM. Host-Directed therapies for tuberculosis. Cold Spring Harb Perspect Med. (2015) 5:10. doi: 10.1101/cshperspect.a021196

58. Thuong NTT, Heemskerk D, Tram TTB, Thao LTP, Ramakrishnan L, Ha VTN, et al. Leukotriene a4 hydrolase genotype and HIV infection influence intracerebral inflammation and survival from tuberculous meningitis. J Infect Dis. (2017) 215:1020-8. doi: 10.1093/infdis/jix050

59. van Laarhoven A, Dian S, Ruesen C, Hayati E, Damen M, Annisa J, et al. Clinical parameters, routine inflammatory markers, and LTA4H genotype as predictors of mortality among 608 patients with tuberculous meningitis in indonesia. J Infect Dis. (2017) 215:1029-39. doi: 10.1093/infdis/ jix051

60. Fava VM, Schurr E. Evaluating the impact of LTA4H genotype and immune status on survival from tuberculous meningitis. J Infect Dis. (2017) 215:10113. doi: 10.1093/infdis/jix052

61. Donovan J, Phu NH, Thao LTP, Lan NH, Mai NTH, Trang NTM, et al. Adjunctive dexamethasone for the treatment of HIV-uninfected adults with tuberculous meningitis stratified by leukotriene a4 hydrolase genotype (LAST ACT): study protocol for a randomised double blind placebo controlled non-inferiority trial. Wellcome Open Res. (2018) 3:32. doi: 10.12688/wellcomeopenres.14007.1

62. van Laarhoven A, Dian S, Aguirre-Gamboa R, Avila-Pacheco J, RicanoPonce I, Ruesen C, et al. Cerebral tryptophan metabolism and outcome of tuberculous meningitis: an observational cohort study. Lancet Infect Dis. (2018) 18:526-35. doi: 10.1016/S1473-3099(18)30053-7

63. Hill AV. Evolution, revolution and heresy in the genetics of infectious disease susceptibility. Philos Trans R Soc Lond B Biol Sci. (2012) 367:8409. doi: 10.1098/rstb.2011.0275

64. Ansari MA, Pedergnana V, C LCI, Magri A, Von Delft A, Bonsall D, et al. Genome-to-genome analysis highlights the effect of the human innate and adaptive immune systems on the hepatitis c virus. Nat Genet. (2017) 49:66673. doi: $10.1038 / \mathrm{ng} .3835$

65. Alkabab Y, Keller S, Dodge D, Houpt E, Staley D, Heysell S. Early interventions for diabetes related tuberculosis associate with hastened sputum microbiological clearance in Virginia, USA. BMC Infect Dis. (2017) 17:125. doi: 10.1186/s12879-017-2226-y

66. Alsultan A, Peloquin CA. Therapeutic drug monitoring in the treatment of tuberculosis: an update. Drugs. (2014) 74:83954. doi: 10.1007/s40265-014-0222-8

67. Srivastava S, Pasipanodya JG, Meek C, Leff R, Gumbo T. Multidrug-resistant tuberculosis not due to noncompliance but to between-patient pharmacokinetic variability. J Infect Dis. (2011) 204:1951-9. doi: 10.1093/infdis/jir658

68. Song T, Lee M, Jeon HS, Park Y, Dodd LE, Dartois V, et al. Linezolid trough concentrations correlate with mitochondrial toxicity-Related adverse events in the treatment of chronic extensively drug-Resistant tuberculosis. EBioMed. (2015) 2:1627-33. doi: 10.1016/j.ebiom.2015.09.051

69. Magis-Escurra C, Later-Nijland H, Alffenaar J, Broeders J, Burger D, van Crevel R, et al. Population pharmacokinetics and limited sampling strategy for first-line tuberculosis drugs and moxifloxacin. Int J Antim Agents. (2014) 44:229-34. doi: 10.1016/j.ijantimicag.2014.04.019

70. van Beek SW, Ter Heine R, Keizer RJ, Magis-Escurra C, Aarnoutse RE, Svensson EM. Personalized tuberculosis treatment through modelInformed dosing of rifampicin. Clin Pharmacokinet. (2019) 58:81526. doi: 10.1007/s40262-018-00732-2

71. Han M, Jun SH, Lee JH, Park KU, Song J, Song SH. Method for simultaneous analysis of nine second-line anti-tuberculosis drugs using UPLC-MS/MS. J Antimicrob Chemother. (2013) 68:2066-73. doi: 10.1093/jac/ dkt154

72. Ruesen C, Riza AL, Florescu A, Chaidir L, Editoiu C, Aalders N, et al. Linking minimum inhibitory concentrations to whole genome sequence-predicted drug resistance in Mycobacterium tuberculosis strains from romania. Sci Rep. (2018) 8:9676. doi: 10.1038/s41598-018-27962-5

73. Vu DH, Koster RA, Alffenaar JW, Brouwers JR, Uges DR. Determination of moxifloxacin in dried blood spots using LC-MS/MS and the impact of the hematocrit and blood volume. J Chromatogr B Analyt Technol Biomed Life Sci. (2011) 879:1063-70. doi: 10.1016/j.jchromb.2011.03.017

74. Vu DH, Alffenaar JW, Edelbroek PM, Brouwers JR, Uges DR. Dried blood spots: a new tool for tuberculosis treatment optimization. Curr Pharm Design. (2011) 17:2931-9. doi: 10.2174/138161211797470174

75. Srivastava S, Gumbo T. In vitro and in vivo modeling of tuberculosis drugs and its impact on optimization of doses and regimens. Curr Pharm Design. (2011) 17:2881-8. doi: 10.2174/138161211797470192

76. Dorman SE, Schumacher SG, Alland D, Nabeta P, Armstrong DT, King B, et al. Xpert MTB/RIF ultra for detection of Mycobacterium tuberculosis and rifampicin resistance: a prospective multicentre diagnostic accuracy study. Lancet Infect Dis. (2018) 18:76-84. doi: 10.1016/S1473-3099(17)30691-6

77. Nathavitharana RR, Cudahy PG, Schumacher SG, Steingart KR, Pai M, Denkinger CM. Accuracy of line probe assays for the diagnosis of pulmonary and multidrug-resistant tuberculosis: a systematic review and meta-analysis. Eur Respir J. (2017) 49:1. doi: 10.1183/13993003.01075-2016

78. Bjerrum S, Schiller I, Dendukuri N, Kohli M, Nathavitharana RR, Zwerling AA, et al. Lateral flow urine lipoarabinomannan assay for detecting active tuberculosis in people living with HIV. Cochrane Database Syst Rev. (2019) 10:CD011420. doi: 10.1002/14651858.CD011420.pub3

79. Heyckendorf J, Labugger I, van der Merwe L, Garcia-Basteiro AL, Diacon AH, Lange C. Serial measurements of transrenal mycobacterial DNA as indicators 
of the early bactericidal activity (EBA) of antituberculosis drugs. Tuberculosis. (2017) 102:31-3. doi: 10.1016/j.tube.2016.10.005

80. Labugger I, Heyckendorf J, Dees S, Haussinger E, Herzmann C, Kohl TA, et al. Detection of transrenal DNA for the diagnosis of pulmonary tuberculosis and treatment monitoring. Infection. (2017) 45:269-76. doi: 10.1007/s15010-016-0955-2

81. Gupta-Wright A, Corbett EL, van Oosterhout JJ, Wilson D, Grint D, Alufandika-Moyo M, et al. Rapid urine-based screening for tuberculosis in HIV-positive patients admitted to hospital in africa (STAMP): a pragmatic, multicentre, parallel-group, double-blind, randomised controlled trial. Lancet. (2018) 392:292-301. doi: 10.1016/S0140-6736(18)31267-4

82. Broger T, Nicol MP, Szekely R, Bjerrum S, Sossen B, Schutz C, et al. Diagnostic accuracy of a novel tuberculosis point-of-care urine lipoarabinomannan assay for people living with HIV: a meta-analysis of individual in- and outpatient data. PLoS Med. (2020) 17:e1003113. doi: 10.1371/journal.pmed.1003113

83. DiNardo AR, Kay AW, Maphalala G, Harris NM, Fung C, Mtetwa G, et al. Diagnostic and treatment monitoring potential of a Stool-Based quantitative polymerase chain reaction assay for pulmonary tuberculosis. Am J Trop Med Hyg. (2018) 99:310-6. doi: 10.4269/ajtmh.18-0004

84. Portevin D, Moukambi F, Clowes P, Bauer A, Chachage M, Ntinginya $\mathrm{NE}$, et al. Assessment of the novel t-cell activation markertuberculosis assay for diagnosis of active tuberculosis in children: a prospective proof-of-concept study. Lancet Infect Dis. (2014) 14:931-8. doi: 10.1016/S1473-3099(14)70884-9

85. Suliman S, Thompson E, Sutherland J, Weiner Rd J, Ota MOC, Shankar S, et al. Four-gene pan-African blood signature predicts progression to tuberculosis. Am J Respir Crit Care Med. (2018) 197:1198-208. doi: 10.1164/rccm.201711-23400C

86. Zak DE, Penn-Nicholson A, Scriba TJ, Thompson E, Suliman S, Amon LM, et al. A blood RNA signature for tuberculosis disease risk: a prospective cohort study. Lancet. (2016) 387:2312-22. doi: 10.1016/S0140-6736(15) 01316-1

87. Penn-Nicholson A, Mbandi SK, Thompson E, Mendelsohn SC, Suliman S, Chegou NN, et al. RISK6, a 6-gene transcriptomic signature of TB disease risk, diagnosis and treatment response. Sci Rep. (2020) 10:8629. doi: 10.1101/19006197

88. Gupta RK, Turner CT, Venturini C, Esmail H, Rangaka MX, Copas A, et al. Concise whole blood transcriptional signatures for incipient tuberculosis: a systematic review and patient-level pooled meta-analysis. Lancet Respir Med. (2020) 8:395-406. doi: 10.1016/S2213-2600(19) 30282-6

89. Murphy K, Habib SS, Zaidi SMA, Khowaja S, Khan A, Melendez J, et al. Computer aided detection of tuberculosis on chest radiographs: an evaluation of the CAD4TB v6 system. Sci Rep. (2020) 10:5492. doi: 10.1038/s41598-020-62148-y

90. Friedrich SO, Rachow A, Saathoff E, Singh K, Mangu CD, Dawson R, et al. Assessment of the sensitivity and specificity of xpert MTB/RIF assay as an early sputum biomarker of response to tuberculosis treatment. Lancet Resp Med. (2013) 1:462-70. doi: 10.1016/S2213-2600(13)70119-X
91. Sabiiti W, Azam K, Kuchaka D, Mtafya B, Bowness R, Oravcova K, et al. Improving diagnosis and monitoring of treatment response in pulmonary tuberculosis using the molecular bacterial load assay (MBLA). bioRxiv. (2019) 2019:555995. doi: 10.3791/60460

92. Sabiiti W, Azam K, Farmer ECW, Kuchaka D, Mtafya B, Bowness R, et al. Tuberculosis bacillary load, an early marker of disease severity: the utility of tuberculosis molecular bacterial load assay. Thorax. (2020) doi: 10.1136/thoraxjnl-2019-214238

93. Honeyborne I, McHugh TD, Phillips PP, Bannoo S, Bateson A, Carroll N. Molecular bacterial load assay, a culture-free biomarker for rapid and accurate quantification of sputum Mycobacterium tuberculosis bacillary load during treatment. J Clin Microbiol. (2011) 49:11. doi: 10.1128/JCM.00547-11

94. Ahmed MIM, Ziegler C, Held K, Dubinski I, Ley-Zaporozhan J, Geldmacher $\mathrm{C}$, et al. The TAM-TB assay-A promising TB immune-diagnostic test with a potential for treatment monitoring. Front Pediatr. (2019) 7:27. doi: $10.3389 /$ fped.2019.00027

95. Ahmed MIM, Ntinginya NE, Kibiki G, Mtafya BA, Semvua H, Mpagama $\mathrm{S}$, et al. Phenotypic changes on Mycobacterium tuberculosis -Specific CD4t Cells as surrogate markers for tuberculosis treatment efficacy. Front Immunol. (2018) 9:2247. doi: 10.3389/fimmu.2018.02247

96. Malherbe ST, Shenai S, Ronacher K, Loxton AG, Dolganov G, Kriel M, et al. Persisting positron emission tomography lesion activity and Mycobacterium tuberculosis MRNA after tuberculosis cure. Nature medicine. (2016) 22:1094100. doi: $10.1038 / \mathrm{nm} .4177$

97. Darboe F, Mbandi SK, Naidoo K, Yende-Zuma N, Lewis L, Thompson EG, et al. Detection of tuberculosis recurrence, diagnosis and treatment response by a blood transcriptomic risk signature in HIVInfected persons on antiretroviral therapy. Front Microbiol. (2019) 10:1441. doi: 10.3389/fmicb.2019.01441

98. Thompson EG, Du Y, Malherbe ST, Shankar S, Braun J, Valvo J, et al. Host blood RNA signatures predict the outcome of tuberculosis treatment. Tuberculosis (Edinb). (2017) 107:48-58. doi: 10.1016/j.tube.2017.08.004

Conflict of Interest: JH, MR, and CL have filed a patent for a 22-gene model to predict the end of therapy of TB treatment (EP20158652.6).

The remaining authors declare that the research was conducted in the absence of any commercial or financial relationships that could be construed as a potential conflict of interest.

Copyright $\odot 2020$ Lange, Aarnoutse, Chesov, van Crevel, Gillespie, Grobbel, Kalsdorf, Kontsevaya, van Laarhoven, Nishiguchi, Mandalakas, Merker, Niemann, Köhler, Heyckendorf, Reimann, Ruhwald, Sanchez-Carballo, Schwudke, Waldow and DiNardo. This is an open-access article distributed under the terms of the Creative Commons Attribution License (CC BY). The use, distribution or reproduction in other forums is permitted, provided the original author(s) and the copyright owner(s) are credited and that the original publication in this journal is cited, in accordance with accepted academic practice. No use, distribution or reproduction is permitted which does not comply with these terms. 